\title{
A NOTE ON THE CONSTITUTIVE LAW FOR SEA ICE
}

\author{
By Ronald B. Smith \\ (Department of Geology and Geophysics, Yale University, New Haven, Connecticut 06520, \\ U.S.A.)
}

\begin{abstract}
The derivation of a constitutive law to describe large-scale sea-ice deformation commonly uses the so-called "flow rule". This method introduces a mathematically imposed relationship between shear strength and dilatation which is not based on physical postulates. In this note a more general procedure is described which uses the Reiner-Rivlin equation as a starting point. The method is illustrated by deriving a particular constitutive law and applying it to a simple problem of sea ice blown against a shoreline.

RÉsumÉ. Une note sur la loi de constitution de la glace de mer. L'établissement d'une loi constitutive pour décrire la déformation à grande échelle de la glace de mer utilise couramment ce qu'on appelle la «règle d'écoulement». Cette méthode introduit une relation, mathématiquement imposée, entre la contrainte de cisaillement et la dilatation qui n'est pas basée sur des hypothèses physiques. Dans cette note on décrit un mode de calcul plus général qui utilise l'équation de Reiner-Rivlin comme point de départ. La méthode est illustrée par l'établissement d'une loi constitutive particulière et en l'appliquant à un problème simple d'accumulation de glace de mer par le vent contre un rivage.
\end{abstract}

ZusammenFassung. Eine Bemerkung zum Grundgesetz für Meereis. Die Ableitung eines Grundgesetzes zur Beschreibung grossräumiger Meereisdeformationen benutzt gewöhnlich das sog. „Fliessgesetz”. Diese Methode führt eine mathematisch hergeleitete Beziehung zwischen der Scherfestigkeit und der Verlagerung ein, die nicht auf physikalischen Postulaten beruht. In dieser Bermerkung wird ein allgemeineres Verfahren beschrieben, das von der Reiner-Rivlin-Gleichung ausgeht. Das Verfahren wird durch die Ableitung eines speziellen Grundgesetzes erläutert, das auf das einfache Problem des Andriftens von Meereis gegen eine Küste angewandt wird.

OVER the past ten years considerable attention has been paid to the development of a continuum model of large-scale sea-ice deformation (see recent reviews by Hibler, 1980, and Coon, [ $\left.{ }^{\mathrm{C}} 1980\right]$ ). The most commonly used constitutive law is derived from a yield curve using a "flow rule" (e.g. Coon, 1974; Rothrock, 1975; Hibler, 1977, 1979; Ralston [ ${ }^{\mathrm{c}} 1980$ ]). The purpose of this note is to point out an alternative derivation for the constitutive law which, while still using a yield curve, avoids using the flow rule and thereby avoids the mathematically imposed relationship between dilatation and pressuredependent shear strength which the flow rule implies.

Consider the tear-shaped yield of Rothrock (1975) shown in Figure 1. In region A, the yield curves widen indicating an increase in the shear strength with increasing isotropic compressive stress $-\frac{1}{2}\left(\sigma_{1}+\sigma_{2}\right)$. This is a realistic feature of the model but, as is well known, the use of the flow rule

$$
\dot{\varepsilon}_{i j}=\lambda \frac{\partial \mathrm{f}}{\partial \sigma_{i j}}
$$

(with $\mathrm{f}\left(\sigma_{1}, \sigma_{2}\right)=0$ on the yield curve) in this region also implies a definite rate of steady divergence. It is certainly true that some materials do dilate initially when they are sheared, but there is no physical law which would require continuing dilatation for all materials whose yield curves diverge.

In region $\mathrm{B}$, the yield curve narrows and cuts across the isotropic stress axis. With the flow rule in mind, this geometry of yield curve is chosen to describe the tendency of the ice to converge under conditions of large compressive isotropic stress. Unfortunately, this geometry carries with it the prediction that the shear strength will weaken with increasing isotropic stress.

It should be clear that to retain full flexibility in choosing a constitutive law, the mathematically convenient flow rule must be avoided. It cannot, after all, be derived rigorously for pressure-dependent materials (Hunter, 1976), and its implications are unphysical. In its place we propose a more general 


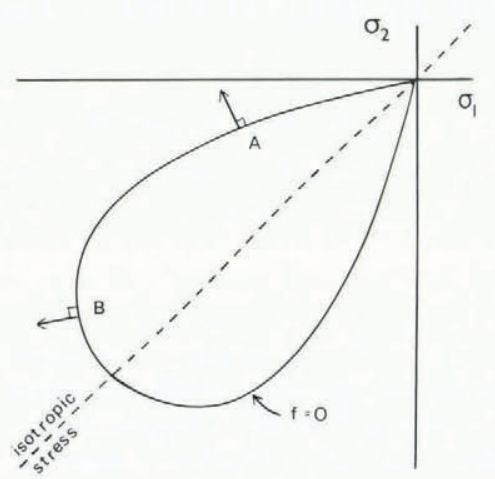

Fig. 1. The tear-shaped yield curve of Rothrock (1975). The axes $\sigma_{1}$ and $\sigma_{2}$ are the two principal stresses at a point. The yield curve is described by $f\left(\sigma_{1}, \sigma_{2}\right)=0$. A value of stress near point $A$ would produce a shearing deformation and, according to the flow rule, a dilatation. Near point $B$, the yield curve narrows to describe ice convergence but this also implies a shear strength which decreases with increasing normal stress.

procedure starting with the Reiner-Rivlin equation. To illustrate this procedure, consider a twodimensional continuum with the following properties.

(1) No equilibium pressure - the ice has no tendency to expand of its own accord (although it might do so because of random wind or current forcing).

(2) No ability to support tension - the ice is presumed to be already cracked in several directions.

(3) Resistance to deviatoric shearing is proportional to the isotropic compressive stress holding the ice floes together, and independent of the strain-rate and ice thickness - this is analogous to the Coulomb law for granular materials (Coon, 1974).

(4) The ice is nearly non-divergent until a critical value of isotropic stress is reached. Choosing this critical stress proportional to the ice thickness is consistent with the ice-ridging energy analysis of Rothrock (1975). We further assume, for the present purposes, that this process is independent of on-going shearing.

(5) The ice is horizontally isotropic.

The Reiner-Rivlin equation is the most general local constitutive relation that satisfies condition (5). In two dimensions it reduces to

$$
\sigma_{i j}=\hat{\gamma}\left(\mathbf{S}_{i}, \theta_{1}, \theta_{2}\right) \delta_{i j}+\hat{\mu}\left(\mathbf{S}_{i}, \theta_{1}, \theta_{2}\right) \dot{\varepsilon}_{i j}
$$

where the $\mathbf{S}_{i}$ are any of a number of scalar state variables and $\theta_{1}, \theta_{2}$ are the two invariants of the strainrate tensor

$$
\begin{gathered}
\theta_{1}=\dot{\varepsilon}_{i i}, \\
\theta_{2}=\dot{\varepsilon}_{i j} \dot{\varepsilon}_{i j},
\end{gathered}
$$

and

$$
\dot{\varepsilon}_{i j}=\frac{1}{2}\left(\frac{\partial u_{i}}{\partial x_{j}}+\frac{\partial u_{j}}{\partial x_{i}}\right), \quad i, j=1,2 .
$$

The functions $\hat{\gamma}$ and $\hat{\mu}$ are to be chosen to satisfy conditions (1)--(4). This procedure is simplified if we split the stress tensor into its isotropic and deviatoric parts in the usual way.

Then

$$
\sigma_{i j}=\gamma\left(\mathbf{S}_{i}, \theta_{1}, \theta_{2}\right) \delta_{i j}+\mu\left(\mathbf{S}_{i}, \theta_{1}, \theta_{2}\right) \dot{\varepsilon}_{i j}^{\prime}
$$


where

$$
\begin{gathered}
\dot{\varepsilon}_{i j}^{\prime}=\dot{\varepsilon}_{i j}-\frac{1}{2} \dot{\varepsilon}_{i i}, \\
\gamma=\hat{\gamma}+\frac{\hat{\mu}}{2} \theta_{1},
\end{gathered}
$$

and $\mu=\hat{\mu}$. The pressure, defined as

$$
p=-\frac{1}{2} \sigma_{i i}
$$

is

$$
p=-\gamma\left(\mathbf{S}_{i}, \theta_{1}, \theta_{2}\right),
$$

while the deviatoric stress

$$
\sigma_{i j}+p \delta_{i j}=\mu\left(\mathrm{S}_{i}, \theta_{1}, \theta_{2}\right) \dot{\varepsilon}_{i j}^{\prime} .
$$

Condition (4) can be satisfied by choosing the viscosity function $\gamma$ to be any function which is zero during ice divergence, but which allows the stress to rise quickly to a limiting value (dependent on ice thickness) for ice convergence. An example of such a function is

$$
\begin{aligned}
\gamma=\gamma\left(h, \theta_{1}\right) & =-C(h)\left(\theta_{1} / \bar{\theta}_{1}\right)^{1 / n} & & \theta_{1} \leqslant 0 \\
& =0 & & \theta_{1} \geqslant 0
\end{aligned}
$$

where $C(h)$ is a thickness-dependent yield stress for the onset of rapid convergence. With the constant $n$ taken to be large, Equation (11) is nearly unaffected by the choice of the normalizing factor $\bar{\theta}_{1}$, and the dilatation rate $\theta_{1}$ becomes vanishingly small unless the isotropic stress is close to $C$. Note that (1) is satisfied by Equation (11) as

$$
p=\gamma=0 \quad \text { when } \theta_{1}=0 .
$$

The desired behavior for the deviatoric stress (condition (3)) can be obtained by choosing

$$
\mu=\mu\left(p, \theta_{2}\right) .
$$

The crucial step here is using the pressure $p$ as a state variable in the Reiner-Rivlin constitutive relation. This choice is physically and mathematically correct as the pressure is a scalar invariant of the system. The fact that it makes the constitutive relation transcendental (i.e. the viscosity function now depends on a stress) causes no difficulty, either for statically determinate or indeterminate problems. This is so because the constitutive relation must in any case be solved simultaneously with the other field equations.

For incompressible materials this method is the only way of representing Coulomb behavior within the Reiner-Rivlin system as the rate-of-divergence $\dot{\varepsilon}_{t t}$ contains no information about the level of isotropic stress. For compressible materials other procedures could be used, but this is probably the most convenient way as it explicitly displays the influence of isotropic stress on shear strength. Note also that there is no conflict between the use of pressure as a state variable in $\mu$, and the lack of volumetric elasticity implied by condition (1).

An example of Equation (13) which satisfies condition (3) is

$$
\begin{aligned}
\mu\left(p, \theta_{2}\right) & =D p\left(\theta_{2} / \bar{\theta}_{2}\right)^{-1 / 2(1-1 / n)} & & p \geqslant 0, \\
& =0 & & p \leqslant 0 .
\end{aligned}
$$

If again $n$ is taken to be large, the constant $D$ may be interpreted as a coefficient of sliding or internal friction. The magnitude of $D$ determines the angle between the yield curve and the isotropic stress axis. We require $D \leqslant 1$ in order to satisfy condition (2).

The choice of how large to make $n$ in Equations (11) and (14) depends on how sharp a transition exists between rigid and plastic behavior. For large $n$, a description in terms of a yield curve (Fig. 2) is appropriate. Note that in this model, the effect of ice thickness on shear strength is indirect. Under compression, the thicker ice can withstand a larger pressure and therefore, through its Coulomb behavior, have an increased shear strength. 


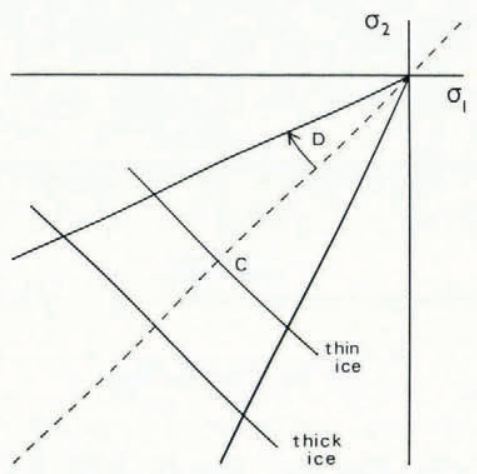

Fig. 2. An example of a yield curve consistent with postulates (1)-(5), and with isotropic and deviatoric stresses treated independently. The angle $D$ describes the increase of shear strength with normal stress. The function $C(h)$ describes the thickness-dependent strength by which the ice resists convergence.

The use of this constitutive relation can be illustrated by examining the (statically determinate) problem of a belt of sea ice blown against a straight infinite coastline by a wind stress with on-shore and long-shore components $\tau_{\perp}$ and $\tau_{\|}$respectively. (This problem is equivalent to the problem of a viscous or granular material resting on an inclined plane under the influence of gravity. In both problems, the normal and tangential stress increase proportionately away from the free boundary. The tilt angle of the plane is equivalent to the angle of the wind-stress vector). Neglecting the Coriolis force and the frictional forces beneath the ice, the stress supported by the ice is

$$
\left.\begin{array}{rl}
\sigma_{x x} & =\tau_{\perp} x \\
\sigma_{x y} & =\tau_{\|} x,
\end{array}\right\}
$$

where $x$ is measured shoreward of the ice edge (see Fig. 3). The value of $\sigma_{y y}$ is determined by the following argument. Along a very long coast even a slight long-shore divergence would produce large long-shore velocities which would be resisted by friction. Thus locally, $\sigma_{y y}$ will take on a value equal to $\sigma_{x x}$. A similar result would follow if the shoreline were slightly curved forming a large closed basin. This stress field could be represented on Figure 2 as a straight line emanating from the origin at an angle $\phi$ from the isotropic stress axis. In the case of small $\phi$ (nearly on-shore winds) the stress trajectory remains in the nearly rigid field until the normal stress condition for the initial thickness $\left(h_{0}\right)$ is exceeded at position $x_{1}$.

From Equations (9), (11), and (15)

$$
\tau_{\perp} x_{1}=C\left(h_{0}\right) .
$$

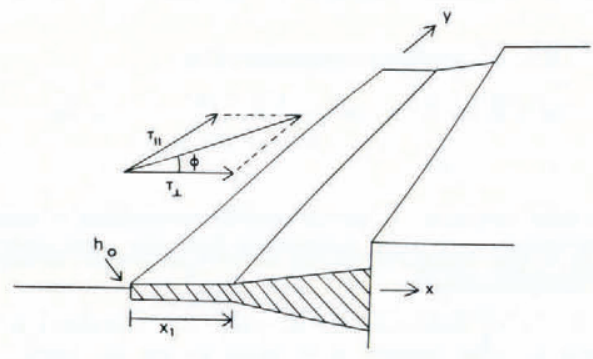

Fig. 3. A belt of sea ice of initial thickness $h_{0}$ blown against a shoreline. The wind stress vector has both on-shore $\tau_{\perp}$ and long-shore $\tau_{\|}$components. Beyond the point $x_{1}$ the ice thickens to withstand the increasing normal stress. When the wind angle $\phi$ increases to $\phi=D$, the ice will begin to move along the coast. 
Beyond that point the ice thickness increases according to

$$
\tau_{\perp} x=C(h) .
$$

As the wind stress angle $\phi$ increases, the stress trajectory eventually coincides with the shearing yield curve $\phi=D$. Under these conditions shearing motion begins simultaneously all across the ice belt, in both the thickened and unthickened regions. (This is analogous to the angle-of-repose in the inclined plane problem). This result is very sensitive to choice of yield-curve shape. If the product $D p$ in Equation (14) were replaced by a more general function $g(p)$, the curvature of this function (and therefore the curvature of the yield curve) would determine whether shearing would be initiated at the shore or at the ice edge.

The use of the flow rule in this problem would lead to a somewhat different result. When the on-shore wind-angle $\phi$ increased sufficiently to produce shearing motion, the flow rule predicts that the ice would begin to expand outwards away from the coast. This expansion would continue indefinitely, or at least until the ice became so thin that it could not withstand the existing isotropic stresses.

\section{SUMMARY}

The object of this note is to suggest a procedure whereby the transition between nearly rigid and nearly plastic sea-ice behavior can be represented mathematically. The method is to use the Reiner-Rivlin equation with pressure included as a state variable and the two viscosity functions chosen to satisfy various empirical constraints. The "flow rule" is not appropriate for this kind of problem as sea ice is a compressible medium. The relationship between shear strength and compressibility predicted by the flow rule is not physically or empirically based, although it may in some circumstances appear reasonable.

The particular viscosity functions in Equations (11) and (14) are derived from conditions (1)-(4), and the solutions to the ice-belt problem are presented for illustrative purposes only. They are not meant to be representative of actual sea-ice dynamics. The author hopes that with a more careful and extensive list of empirical and physical constraints, a useful constitutive relation could be derived.

\section{ACKNOWLEDGEMENTS}

My interest in this problem stems from several stimulating conversations with W. D. Hibler and R. E. Moritz.

MS. received 3 March 1982

\section{REFERENCES}

Coon, M. D. 1974. Mechanical behavior of compacted Arctic ice floes. Journal of Petroleum Technology, Vol. 26, No. 4, p. 466-70.

Coon, M. D. ['1980.] A review of AIDJEX modeling. (In Pritchard, R. S., ed. Sea ice processes and models. Proceedings of the Arctic Ice Dynamics Joint Experiment/International Commission on Snow and Ice symposium. Seattle and London, University of Washington Press, p. 12-27. [IAHS-AISH Publication No. 124.])

Hibler, W. D., III. 1977. A viscous sea ice law as a stochastic average of plasticity. Journal of Geophysical Research, Vol. 82, No. 27, p. 3932-38.

Hibler, W. D., III. 1979. A dynamic thermodynamic sea ice model. Journal of Physical Oceanography, Vol. 9, No. 4, p. $815-46$.

Hibler, W. D., III. 1980. Sea ice growth, drift, and decay. (In Colbeck, S. C., ed. Dynamics of snow and ice masses. New York, etc., Academic Press, p. 141-209.)

Hunter, S. C. 1976. Mechanics of continuous media. Chichester, E. Horwood; New York, Halsted Press.

Pritchard, R. S. 1975. An elastic-plastic constitutive law for sea ice. Transactions of the American Society of Mechanical Engineers. Ser. E. Journal of Applied Mechanics, Vol. 42, No. 2, p. 379-84.

Ralston, T. D. [ $\left.{ }^{\mathrm{C}} 1980.\right]$ Yield and plastic deformation in ice crushing failure. (In Pritchard, R. S., ed. Sea ice processes and models. Proceedings of the Arctic Ice Dynamics Joint Experiment / International Commission on Snow and Ice symposium. Seattle and London, University of Washington Press, p. 234-45. [IAHS-AISH Publication No. 124.])

Rothrock, D. A. 1975. The energetics of the plastic deformation of pack ice by ridging, Journal of Geophysical Research, Vol. 80, No. 33, p. 4514-19. 